\title{
Effect of Oxygen on Verbenone Conversion From cis-Verbenol by Gut Facultative Anaerobes of Dendroctonus valens
}

\author{
Qingjie Cao ${ }^{1 t}$, Jacob D. Wickham ${ }^{1 \dagger}$, Li Chen ${ }^{1,2}$, Faheem Ahmad ${ }^{3}$, Min $\mathrm{Lu}^{1 *}$ and \\ Jianghua Sun ${ }^{1,2 *}$
}

${ }^{1}$ State Key Laboratory of Integrated Management of Pest Insects and Rodents, Institute of Zoology, Chinese Academy of Sciences, Beijing, China, ${ }^{2}$ University of Chinese Academy of Sciences, Beijing, China, ${ }^{3}$ Department of Biosciences,

COMSATS Institute of Information Technology, Islamabad, Pakistan

OPEN ACCESS

Edited by:

Suhelen Egan,

University of New South Wales,

Australia

Reviewed by:

Benoit Chassaing,

Georgia State University,

United States

David Berry,

University of Vienna, Austria

*Correspondence:

Min Lu

lumin@ioz.ac.cn

Jianghua Sun

sunjh@ioz.ac.cn

tThese authors have contributed equally to this work.

Specialty section: This article was submitted to

Microbial Symbioses, a section of the journa

Frontiers in Microbiology

Received: 15 September 2017 Accepted: 28 February 2018

Published: 16 March 2018

Citation

Cao Q, Wickham JD, Chen L, Ahmad F, Lu M and Sun J (2018)

Effect of Oxygen on Verbenone

Conversion From cis-Verbenol by

Gut Facultative Anaerobes

of Dendroctonus valens.

Front. Microbiol. 9:464.

doi: 10.3389/fmicb.2018.00464
Since its introduction from North America, Dendroctonus valens LeConte has become a destructive forest pest in China. Although gut aerobic bacteria have been investigated and some are implicated in beetle pheromone production, little is known about the abundance and significance of facultative anaerobic bacteria in beetle gut, especially with regards to effects of oxygen on their role in pheromone production. In this study, we isolated and identified gut bacteria of $D$. valens adults in an anaerobic environment, and further compared their ability to convert cis-verbenol into verbenone (a multi-functional pheromone of $D$. valens) under different $\mathrm{O}_{2}$ concentrations. Pantoea conspicua, Enterobacter xiangfangensis, Staphylococcus warneri were the most frequently isolated species among the total of 10 species identified from beetle gut in anaerobic conditions. Among all isolated species, nine were capable of cis-verbenol to verbenone conversion, and the conversion efficiency increased with increased oxygen concentration. This $\mathrm{O}_{2}$-mediated conversion of cis-verbenol to verbenone suggests that gut facultative anaerobes of $D$. valens might play an important role in the frass, where there is higher exposure to oxygen, hence the higher verbenone production. This claim is further supported by distinctly differential oxygen concentrations between gut and frass of D. valens females.

Keywords: oxygen environments, gut facultative anaerobes, pheromone production, cis-verbenol, verbenone

\section{INTRODUCTION}

Symbioses between insects and associated gut microbiota are the driver behind the success of the majority of the destructive pests of forests (Moran et al., 2005; Adams et al., 2011; Sun et al., 2013; Lu et al., 2016). Gut microbiota play an important role in the biology of insects including host's nutrition, development, resistance to pathogens, and reproduction (Brand et al., 1975; Brune, 2003; Moran et al., 2005). In addition to the role in host's nutrition (Kaufman and Klug, 1991; Breznak, 2002), microorganisms may also be involved in complex ecological functions involving pheromone production. Gut-associated microbiota are known to produce components of aggregation pheromones in locusts and sex pheromones in cockroaches (Dillon et al., 2000, 2002; Wada-Katsumata et al., 2015), influence mating preference of Drosophila melanogaster 
(Sharon et al., 2010), and mediate insect interactions with plants by degrading host defense chemicals (Mason et al., 2014) but many of these functions are performed under aerobic condition while their functions under low oxygen conditions has yet to be explored.

Bark beetles (Coleoptera: Curculionidae: Scolytinae) are among the most economically important pests of conifers causing significant losses to pine forests worldwide (Raffa and Berryman, 1987; Paine et al., 1997; Gitau et al., 2013; Wang et al., 2017; Zhou et al., 2017). Previous studies have focused on gut aerobic bacteria in major bark beetle species in order to explain the pests' ecology (Xu et al., 2016c). For example, when exposed to $\alpha$-pinene (a prominent defensive host monoterpene) in the air, the gut-associated Bacillus cereus isolated from Ips paraconfusus produced verbenol (Brand et al., 1975). Similarly, host monoterpene $\alpha$-pinene has been converted to cis- and transverbenol, and myrtenol by bacteria isolated from the bark beetle Ips paraconfusus Lanier (Renwick et al., 1976). $\alpha$-Pinene is a precursor in the biosynthesis of verbenone, one of the common pheromones of bark beetles (Gitau et al., 2013). These findings suggest that microorganisms of bark beetles can counteract the host plant defense molecules.

The red turpentine beetle, Dendroctonus valens LeConte (Scolytinae), is an aggressive, univoltine, tree-killing species and caused mortality of more than 10 million healthy pines in central areas of northern China after it first appeared in Shanxi Province in the late 1990s (Farjon and Page, 1999; Miao et al., 2001; Wang et al., 2012; Sun et al., 2013; Lou et al., 2014; Cheng et al., 2015; Zhou et al., 2016). The beetles overwinter as larvae and complete maturation the following spring. From mid-May to mid-June, adult beetles emerge and then disperse from the parent colony to new host trees through pheromonemediated mass attack (henceforth "dispersing beetles"). Upon successful invasion of new hosts, the beetles penetrate the bark, mate and start oviposition (henceforth "colonizing beetles"). The larvae of colonizing beetles then feed on the phloem, and the cycle continues (Miao et al., 2001). Bioactive chemicals cisverbenol, trans-verbenol, myrtenol, myrtenal, and verbenone are gut volatiles of $D$. valens identified in China (Zhang et al., 2006; Sun et al., 2013; Xu et al., 2016a). Verbenone, in general, is an aggregation pheromones of $D$. valens but its function is concentration dependent where higher concentrations may also act as an anti-aggregation pheromone (Zhang et al., 2006). The concentration of verbenone production in $D$. valens mainly depends upon the rate of conversion of cis-verbenol and transverbenol to verbenone. This conversion is an oxidation process, which was proven to be accelerated by gut-associated bacteria (Xu et al., 2015). However, previous studies on pheromone conversion had not taken in account the in situ oxygen concentration, or anything approximating that. In addition, those studies have been conducted under atmospheric $\mathrm{O}_{2}$ concentrations. Hence, the question stands if these findings are even valid under anaerobic or at least under very low oxygen concentrations.

Therefore, in this study we have investigated the role of gut bacteria involved in verbenone production in $D$. valens under anaerobic and low oxygen conditions. The anaerobic bacteria from the guts of $D$. valens adults in the two life history stages (dispersing and colonizing) were isolated and comparisons of their conversion efficiency of cis-verbenol to verbenone were made under different $\mathrm{O}_{2}$ concentrations. Our findings could further shed light on the role of oxygen on facultative anaerobes in verbenone production and increase understanding of the chemical ecology of red turpentine beetle and bark beetles in general.

\section{EXPERIMENTAL PROCEDURES}

\section{Insects and Media}

Dendroctonus valens adults were captured from newly attacked pine trees in Beishe Mountain and Laoyagou Mountain of Shanxi province during June 2016 (N 37 48', E $111^{\circ} 44^{\prime}$, average elevation $1400 \mathrm{~m}$ ). Each sampling site was about $13 \mathrm{~km}$ apart and infested pine trees were randomly selected at least $200 \mathrm{~m}$ apart to obtain samples of dispersing adult males and females, and colonizing adult males and females.

For the preparation of anaerobic medium, prepared tryptic soy broth (TSB) and tryptic soy agar (TSA) media were gassed with $\mathrm{N}_{2}$ under the atmospheric concentration. The media were dispensed into $18 \mathrm{~mm} \times 150 \mathrm{~mm}$ anaerobic tubes (4 mL/tube) under $\mathrm{N}_{2}$ stream and sealed with butyl rubber stoppers. These tubes were sterilized in an autoclave for $20 \mathrm{~min}$ (Kwon and Ricke, 1998). Pure anaerobic isolates were maintained on TSA plates kept in an anaerobic chamber (ELECTROTEK anaerobic chambers, AW300SG, Britain) with filtered anaerobic gas mixture $\left(80 \% \mathrm{~N}_{2}, 10 \% \mathrm{CO}_{2}\right.$, and $\left.10 \% \mathrm{H}_{2}\right)$.

\section{Chemicals}

In the species specific verbenone conversion experiments, TSA and TSB medium were purchased from Sigma-Aldrich (Shanghai, China). (S)-cis-verbenol (95\% purity), (1S)-(-)-verbenone (94\% purity) and heptyl acetate ( $\geq 98 \%$ purity) were purchased from Sigma-Aldrich (Shanghai, China) for use in all experiments.

\section{Isolation and Identification of Bacteria}

The guts from selected beetles were dissected under anaerobic conditions. Individual guts from adult beetles $(n=120)$ were ground for $10 \mathrm{~s}$ in $200 \mu \mathrm{l}$ of $10 \%$ PBS (phosphate buffer saline solution) and the suspension spread evenly on TSA medium. The dilution factors varied from $10^{2}$ to $10^{6}$. After incubation in anaerobic chamber at $28^{\circ} \mathrm{C}$ for 30 days, colonies of pure bacterial cultures from each sample were selected and streaked. The combination of thickness size, color and size etc. were morphologically categorized and counted for pure cultures.

Samples of isolates were selected for $16 \mathrm{~S}$ rDNA sequencing using DNeasy Blood Kit for extracted DNA (Qiagen, Germany). The $16 \mathrm{~S}$ ribosomal RNA genes were amplified with primers $8 \mathrm{~F} \quad\left(5^{\prime}\right.$-GCGGATCCGCGGCCGCTGCAGAG TTTGATCCTGGCTCAG-3 $\left.{ }^{\prime}\right)$ and 1492R (5'-GGCTCGAG CGGCCGCCCGGGTTACCTTGTTACGACTT-3') (Weisburg et al., 1991). PCR reactions were performed on an Eppendorf Mastercycler Gradient (Eppendorf, Germany). The reaction mixture contained $1.2 \mu \mathrm{l}$ of dNTPs (10 mM each), $5 \mu \mathrm{l}$ of $10 \times$ 
PCR buffer (with $\mathrm{MgCl}_{2}$ ), $2 \mu \mathrm{l}$ of primers (10 $\mu \mathrm{M}$ each), $0.8 \mu \mathrm{l}$

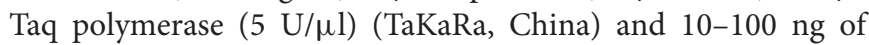
DNA adjusted to $50 \mu \mathrm{l}$ with sterilized deionized water. The reaction conditions were $94^{\circ} \mathrm{C}$ for $5 \mathrm{~min}$; 35 cycles of $30 \mathrm{~s}$ at $94^{\circ} \mathrm{C}, 30 \mathrm{~s}$ at $51^{\circ} \mathrm{C}$, and $1 \mathrm{~min}$ and $30 \mathrm{~s}$ at $72^{\circ} \mathrm{C}$ and a final extension at $72^{\circ} \mathrm{C}$ for $10 \mathrm{~min}$. PCR products with expected size of $1500 \mathrm{bp}$ were visualized on $1 \%$ agarose gels and purified by Axygen DNA Gel Extraction Kit (Axygen, United States). The samples were sequenced in two directions on an ABI 3730XL DNA Analyzer (Applied Biosystems, United States) using the same primers. Consensus sequences were manually assembled and edited according to chromatograms in MEGA5 (Tamura et al., 2011). Alignments were done online using the EzTaxon-e server $^{1}$ (Kim et al., 2012) and BLAST search ${ }^{2}$. Sequences in this study were deposited in the GenBank database (Table 1).

\section{Phylogenetic Analyses}

The identical sequences of the 10 bacterial isolates were subjected to phylogenetic analysis. An additional 35 sequences from the two databases mentioned above, most of which were of type strains and ecologically related strains, were added using Clustal X (Thompson et al., 1997) followed by manual refinement in BIOEDIT (Hall, 1999). jModelTest 2.1 (Darriba et al., 2012), which showed that the GTR+I+G model was the most appropriate model according to the Akaike information criterion (Posada and Buckley, 2004). The phylogeny was constructed by the maximum likelihood approach using RAxML version 7.4.2 (Stamatakis et al., 2004). Confidence at each node was assessed by 1000 bootstrap replicates (Hillis and Bull, 1993). The resulting tree was visualized and edited with Tree Graph 2 (Stöver and

${ }^{1}$ http://www.eztaxon.org/

${ }^{2}$ http://blast.ncbi.nlm.nih.gov/Blast.cgi
Müller, 2010) and refined with Adobe Illustrator CS3. Anabaena affinis (AF247591) was considered as an out group.

\section{Conversion Experiments}

To calculate the cis-verbenol concentration of beetle's hindgut, we followed the methodology described by Vasanthakumar et al. (2006) to determine the ratio of the amount of cis-verbenol in a beetle's hindgut $\left(10^{0}\right.$ to $\left.10^{3} \mathrm{ng}\right)$ to the estimated hindgut volume $(1.21 \pm 0.48 \mu \mathrm{l})$. The cis-verbenol concentration in a beetle's hindgut was estimated in a range from $10^{0}$ to $10^{2} \mathrm{ng} / \mu \mathrm{l}$, hence the concentrations of 4,40 , and $200 \mathrm{ng} / \mu \mathrm{l}$ selected for these experiments. All of the 10 bacterial isolates were grown in TSB medium and incubated for $24 \mathrm{~h}$. A dilution of 1:100 of each isolate was made when cultures were adjusted to an optical density $\left(\mathrm{OD}_{600}\right)$ of 0.5 . Each concentration of cis-verbenol was then added into $4 \mathrm{ml}$ bacterial suspension and shaken for a further $36 \mathrm{~h}$. A suspension containing an equivalent amount of cis-verbenol without bacteria was run as a control in the same manner for each bacterial species tested. All solutions were extracted with hexane and then stored for later chemical analysis to examine verbenone concentration. The conversion experiments followed previosly described methods (Xu et al., 2015), except for incubation and shaking times.

\section{Measurement of $\mathrm{O}_{2}$ Concentrations in Beetle Hindgut and Frass}

Dispersing female and male adult beetles (sexes were distinguished by listening to stridulations produced by males) were captured with the standard $D$. valens lure $[(+)-\alpha$-pinene: $(+)$ - $\beta$-pinene: $(+)$-3-carene $=1: 1: 1]$ in Beishe and Laoyagou mountains of Shanxi province during June 2017. To obtain colonizing beetles, logs (diameter $\geq 30 \mathrm{~cm}$, lengths ${ }^{\circ}=50 \mathrm{~cm}$ )

TABLE 1 | Frequently identified isolates of Dendroctonus valens gut associated facultative bacteria.

\begin{tabular}{|c|c|c|c|c|}
\hline Isolate numbers & Accession numbers & Closest type strains and ecologically related strains & Species affiliation & Similarity (\%) \\
\hline & & & Proteobacteria & \\
\hline & & & Enterobacteriaceae & \\
\hline B3 & MF083086 & Klebsiella michiganensis W14(T) & Klebsiella michiganensis & 99 \\
\hline \multirow[t]{2}{*}{ B1 } & MF083087 & Enterobacter xiangfangensis 10-17(T) & Enterobacter xiangfangensis & 100 \\
\hline & & & Erviniaceae & \\
\hline B6 & MF083088 & Pantoea conspicua LMG 24534(T) & Pantoea conspicua & 99 \\
\hline \multirow[t]{2}{*}{ B2 } & MF083081 & Erwinia sp. FJ811869 (Dendroctonus valens) & Erwinia sp. & 99 \\
\hline & & & Yersiniaceae & \\
\hline B11 & MF083085 & Serratia liquefaciens ATCC 27592(T) & Serratia liquefaciens & 99 \\
\hline B7 & MF083084 & Rahnella variigena CIP 105588(T) & Rahnella variigena & 99 \\
\hline \multirow[t]{3}{*}{ B8 } & MF083083 & Rahnella aquatilis KJ781940 (Dendroctonus valens) & Rahnella aquatilis & 99 \\
\hline & & & Firmicutes & \\
\hline & & & Lactobacillaceae & \\
\hline \multirow[t]{2}{*}{ B4 } & MF083089 & Lactobacillus acidophilus CIP 76.13(T) & Lactobacillus acidophilus & 100 \\
\hline & & & Staphylococcaceae & \\
\hline B13 & MF083080 & Staphylococcus epidermidis ATCC 14990(T) & Staphylococcus epidermidis & 99 \\
\hline B12 & MF083082 & Staphylococcus warneri ATCC 27836(T) & Staphylococcus warneri & 99 \\
\hline
\end{tabular}

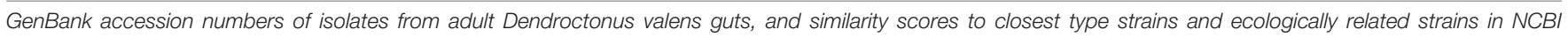
according to the $16 S$ rDNA. "T" indicates type strain and strain in bold indicate ecologically related strain. 


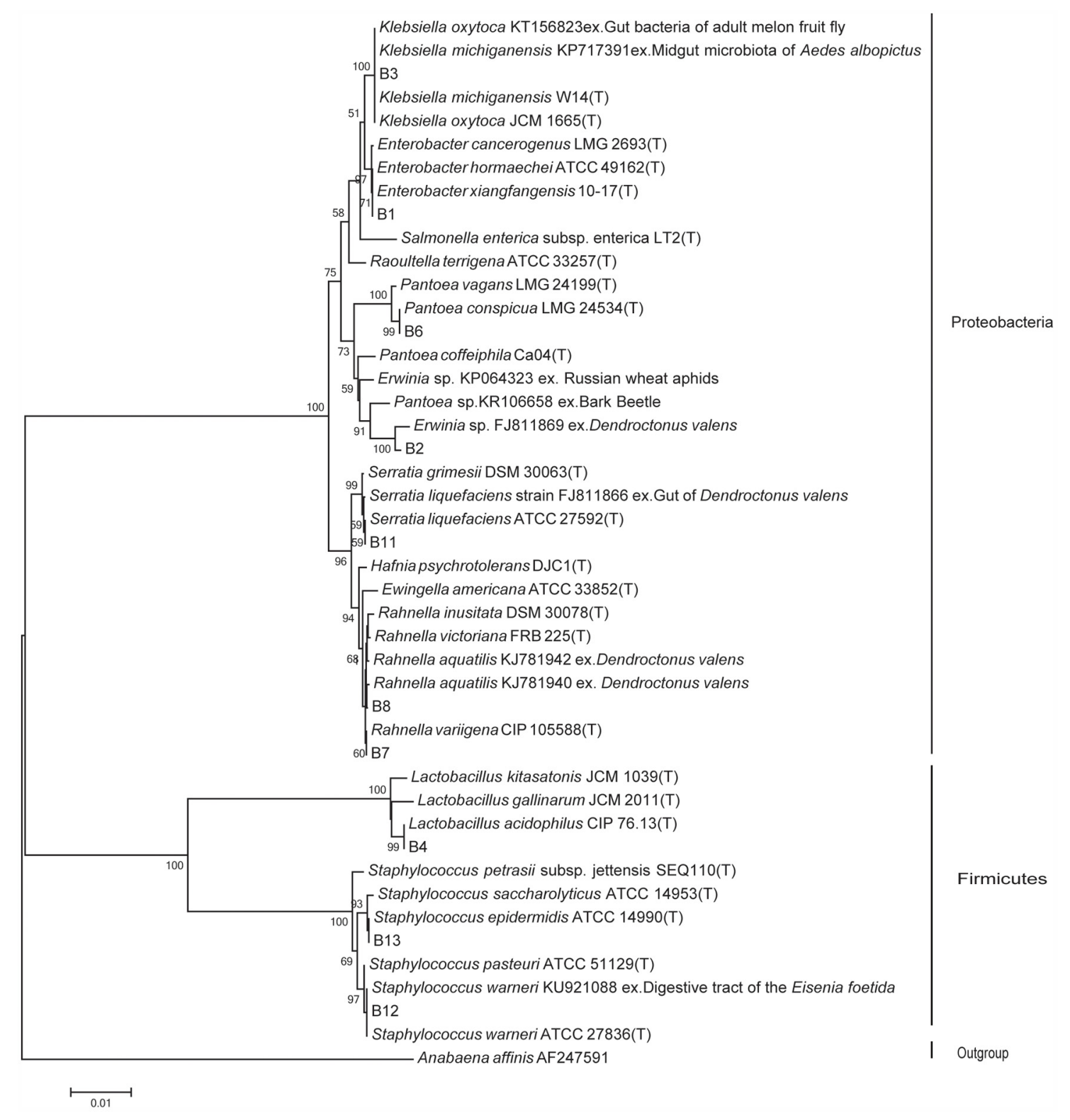

FIGURE 1 | Maximum likelihood tree for the 16S rRNA of Dendroctonus valens gut associated facultative bacteria. The ecologically related (indicated after the accession number with "ex." as the beginning) sequences from GenBank and the types (indicated with "T") from EzTaxon-e database. The 16S rRNA sequence of Anabaena affinis was used as outgroup. Numbers on the nodes represent bootstrap support from 1,000 replicates. Nodes with bootstrap values of $50 \%$ or more are indicated.

were cut from healthy trees and three pairs of adult beetles were introduced to each bolt (four bolts). The ends of the bolts were sealed with wax to keep in moisture, then immediately transported to the laboratory and the beetles allowed to colonize the bolt for a period of 1 month. Of the trapped dispersing beetles, 10 of the healthiest male and female adults were selected for $\mathrm{O}_{2}$ concentration measurement in their hindgut. While for colonizing beetles, 10 males and females were extracted from the bolts. The hindguts of both the female and male adults were extracted and placed on a $2 \mathrm{~mm}$ thick layer of $1.5 \%$ agarose and then covered with a $2 \mathrm{~mm}$ layer of $0.5 \%$ agarose. Clark-type oxygen microelectrodes (tip diameters of $10 \mathrm{~mm}, 90 \%$ response times of $<3 \mathrm{~s}$, and stirring sensitivities of $<2 \%$ ) containing guard cathodes were constructed in our laboratory were used for the measurement of $\mathrm{O}_{2}$ concentrations. Prior to use, the electrodes were polarized for $12 \mathrm{~h}$ in deionized water that was continuously bubbled with air. They were calibrated by measuring the current when the microelectrode was placed in water saturated with air $\left(21 \% \mathrm{O}_{2}\right)$, as well as the background current in water sparged with $100 \% \mathrm{~N}_{2}\left(0 \% \mathrm{O}_{2}\right)$. Calibration was carried out before and after each experiment. The current was measured with a picoammeter (model 1201; Diamond General, Ann Arbor, 
MI, United States) connected to a strip chart recorder. For $\mathrm{O}_{2}$ concentration measurements in frass, microelectrodes used had a tip diameter of $20 \mathrm{~mm}$. Ten pairs of adults were introduced to fresh pine logs for a period of 1 month and the guts of the colonizing beetles (from beetles extracted from the pine logs) were analyzed for $\mathrm{O}_{2}$ concentration. The microelectrode measurements methods described in Brune et al. (1995) were followed, except for $\mathrm{O}_{2}$ concentrations measurements of frass, where microelectrodes were directly probed into the frass in situ.

\section{Comparative Conversion Experiments in Different Oxygen Environments}

Three of the most active bacterial isolates of $D$. valens gut that converted significantly higher amounts of cis-verbenol to verbenone in the previous experiments were selected to test the conversion efficiency under anaerobic conditions, $10 \%(80 \%$ $\mathrm{N}_{2}, 10 \% \mathrm{CO}_{2}$, and $\left.10 \% \mathrm{O}_{2}\right)$ and $20 \%\left(80 \% \mathrm{~N}_{2}\right.$ and $\left.20 \% \mathrm{O}_{2}\right)$ oxygen concentrations, respectively. A suspension containing an equivalent amount of cis-verbenol without bacteria was run as a control in the same manner for each bacterial species tested. The conversion experiments followed previosly described methods.

\section{Chemical Analysis}

The concentrations of verbenone produced during each bio assay were determined using gas chromatography-mass spectrometry. Two microliter extracts were injected, splitless, into GC-MS (Agilent 6980N GC coupled 5973 mass selective detector) equipped with an HP5-MS capillary column $(0.25 \mathrm{~mm}$ i.d. $\times 60 \mathrm{~m}$; Agilent Technologies, Inc., Palo Alto, CA, United States) and the column temperature was programmed from an initial temperature of $50^{\circ} \mathrm{C}$ for $1 \mathrm{~min}$, then ramped $5^{\circ} \mathrm{C} / \mathrm{min}$ to $100^{\circ} \mathrm{C}$, by $3^{\circ} \mathrm{C} / \mathrm{min}$ to $130^{\circ} \mathrm{C}$ and by $20^{\circ} \mathrm{C}$ to $320^{\circ} \mathrm{C}$ ( $2 \mathrm{~min}$ hold time). Components of the extracts were identified by comparing retention times and mass spectra with authentic standards from NIST 02 library (Scientific Instrument Services, Inc., Ringoes, NJ, United States). Quantification was performed using an internal standard (heptyl acetate) that was added to each sample.

\section{Statistical Analysis}

This study used the Scheirer-Ray-Hare test as variances were unequal even after initial data transformation (Dytham, 2011), and Dunnett's $\mathrm{T}^{3}$ test was used for post hoc comparisons. All data were analyzed using SPSS 12.0 (SPSS Inc., Chicago, IL, United States).

\section{RESULTS}

\section{Isolation and Identification of Bacterial Species}

A total of 652 gut facultative bacterial species were isolated from gut samples purified from 120 adult $D$. valens beetles (dispersing male, dispersing female, colonizing female,

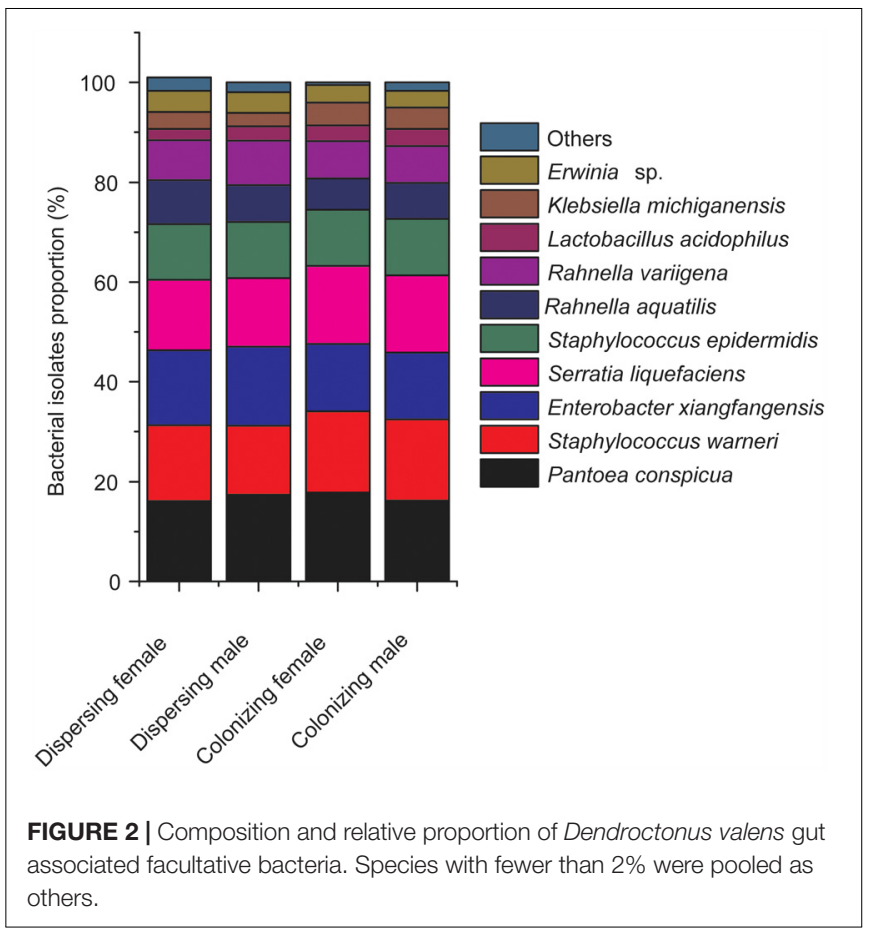

colonizing male, and their phylogeny). BLAST results and phylogenetic analyses were used to identify the isolated species. The results confirmed 10 species of gut facultative bacterial belonging to a total of five families [(viz. Enterobacteriaceae, Erviniaceae, Yersiniaceae, Lactobacillaceae, Staphylococcaceae) and two phyla (viz Proteobacteria (7 species) and Firmicutes (3 species))] (Table 1 and Figure $\mathbf{1}$ ).

Among the identified species, the most frequently isolated species were Pantoea conspicua (dispersing female, 16.1\%; dispersing male, $17.4 \%$; colonizing female, $17.8 \%$; and colonizing male, 16.2\%), Staphylococcus warneri (dispersing female, 15.2\%; dispersing male, $13.8 \%$; colonizing female, $16.3 \%$; and colonizing male, 16.3\%), Enterobacter xiangfangensis (dispersing female, $15 \%$; dispersing male, $15.8 \%$; colonizing female, $13.5 \%$; and colonizing male, 13.4\%) (Figure 2). The remaining species accounted for less than $52 \%$ in both sexes of D. valens adults in the two life history stages. Lactobacillus acidophilus was the least frequently isolated bacterial species.

\section{cis-Verbenol - Verbenone Conversion}

The results of the Scheirer-Ray-Hare test revealed a significant association between bacterial isolates and cis-verbenol concentrations in terms of pheromone production in $D$. valens (Table 2). The amount of verbenone produced by $D$. valens in association with its gut-associated facultative bacterial isolates at three concentrations $(4,40$, and $200 \mathrm{ng} / \mu \mathrm{l})$ of cisverbenol is shown in Figure 3. Nine out of the 10 isolates had resulted into significantly higher concentrations of verbenone compared to control, while no verbenone was detected in facultative bacterial species B4 (L. acidophilus). The highest level of cis-verbenol conversion ability was observed in B1 (E. xiangfangensis), B6 (P. conspicua), and B12 (S. warneri), 
TABLE 2 | Statistics for association between facultative bacteria and pheromone cis-verbenol concentration using Scheirer-Ray-Hare test.

\begin{tabular}{lcccc}
\hline Source & $\boldsymbol{d f}$ & SS & $\boldsymbol{H}$ & $\boldsymbol{P}$-value \\
\hline cis-Verbenol concentrations & 2 & 60720 & 8.23 & $<0.001$ \\
Bacterial isolates & 9 & 14093 & 1.91 & $<0.001$ \\
Bacterial isolates $\times$ cis-verbenol & 18 & 1108 & 0.15 & $<0.001$ \\
concentrations & & & & \\
\hline
\end{tabular}

cis-Verbenol concentrations as independent variables and verbenone production as dependent variable. df, degrees of freedom; SS, sum of squares; $H$, ScheirerRay-Hare non-parametric two-way analysis of variance statistic.

representing the three most frequently isolated species in D. valens guts. Incubation of B1 (E. xiangfangensis) with three concentrations of cis-verbenol yielded $3.68 \pm 0.14,20.18 \pm 0.75$, and $20.71 \pm 0.51 \mathrm{ng} / \mu \mathrm{l}$ of verbenone; B6 (P. conspicua) with three concentrations of cis-verbenol yielded $3.62 \pm 0.27$, $19.54 \pm 9.07$, and $19.83 \pm 9.20 \mathrm{ng} / \mu \mathrm{l}$ of verbenone; B12 (S. warneri) with three concentrations of cis-verbenol yielded $3.35 \pm 0.13,19.33 \pm 0.79$, and $19.43 \pm 0.89 \mathrm{ng} / \mu \mathrm{l}$ of verbenone, respectively.

\section{Measurement of $\mathrm{O}_{2}$ Concentrations in Beetle Hindgut and Frass}

The highest (19.03\%) $\mathrm{O}_{2}$ concentration occurred in frass of D. valens, while the hindgut of male and female beetles had lower $\mathrm{O}_{2}$ concentrations (7.54 and $9.65 \%$, respectively) that were statistically similar but significantly lower than that in the frass (Figure 4). The oxygen concentration in frass was closer to the atmospheric $\mathrm{O}_{2}$ concentration, whereas the average $\mathrm{O}_{2}$ concentration of gut female and gut male oxygen concentration $8.59 \%$, which means the gut is an oxygen-limited microenvironment. These results are very important to evaluate the relevance of the oxygen concentrations used in the conversion experiments.

\section{Comparative Conversion Experiments in Different Oxygen Environments}

In the previous experiments, B1 (E. xiangfangensis), B6 (P. conspicua), and $\mathrm{B} 12$ (S. warneri) isolates of gut bacteria produced the highest concentrations of verbenone, hence these three species were selected to test the oxygen dependent verbenone production. The experiments were conducted under three oxygen concentrations (anaerobic, 10\% and 20\%) and with three concentrations of cis-verbenol (4, 40, and $200 \mathrm{ng} / \mu \mathrm{l})$. Anaerobic and 10\% oxygen concentration was selected as gutsimulated oxygen concentration while the oxygen concentration of $20 \%$ was selected as frass-simulated concentration. The results are presented in Figure 5.

In general, significantly higher concentrations of verbenone were recorded under $20 \%$ oxygen concentration compared to the $10 \%$ oxygen and anaerobic conditions. Whereas, when 40 and $200 \mathrm{ng} / \mu \mathrm{l}$ concentrations of cis-verbenol were offered for conversion, significantly more conversion was observed under $10 \%$ oxygen than the anaerobic conditions. In terms of bacterial efficiencies regarding verbenone production, no significant

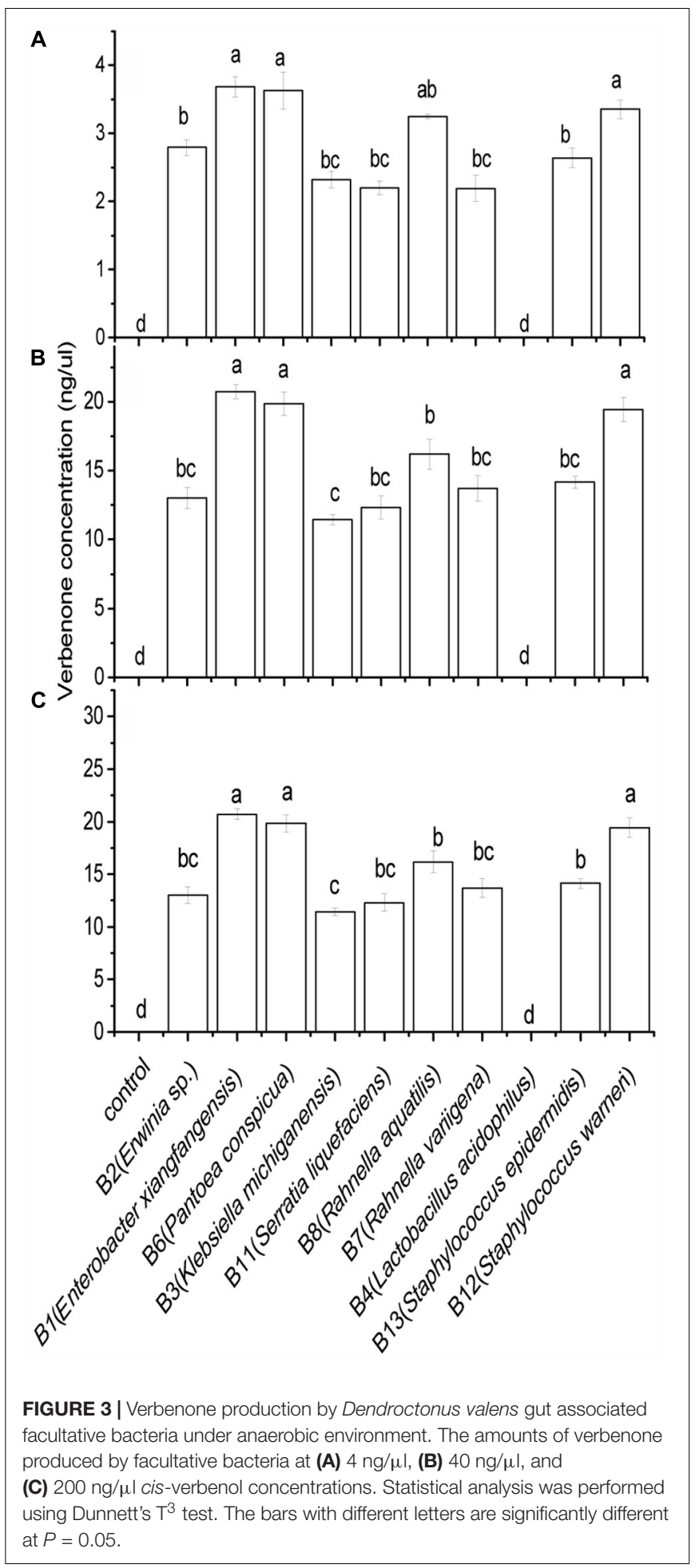

difference was observed at different oxygen concentrations when B1 (E. xiangfangensis) bacterial species was incubated with $4 \mathrm{ng} / \mu \mathrm{l}$ concentrations. Whereas, B6 ( $P$. conspicua) and B12 (S. warneri) converted significantly higher amounts of cis-verbenol to verbenol at $20 \%$ oxygen concentrations when incubated at $4 \mathrm{ng} / \mu \mathrm{l}$ concentrations of $c i s$-verbenol. 


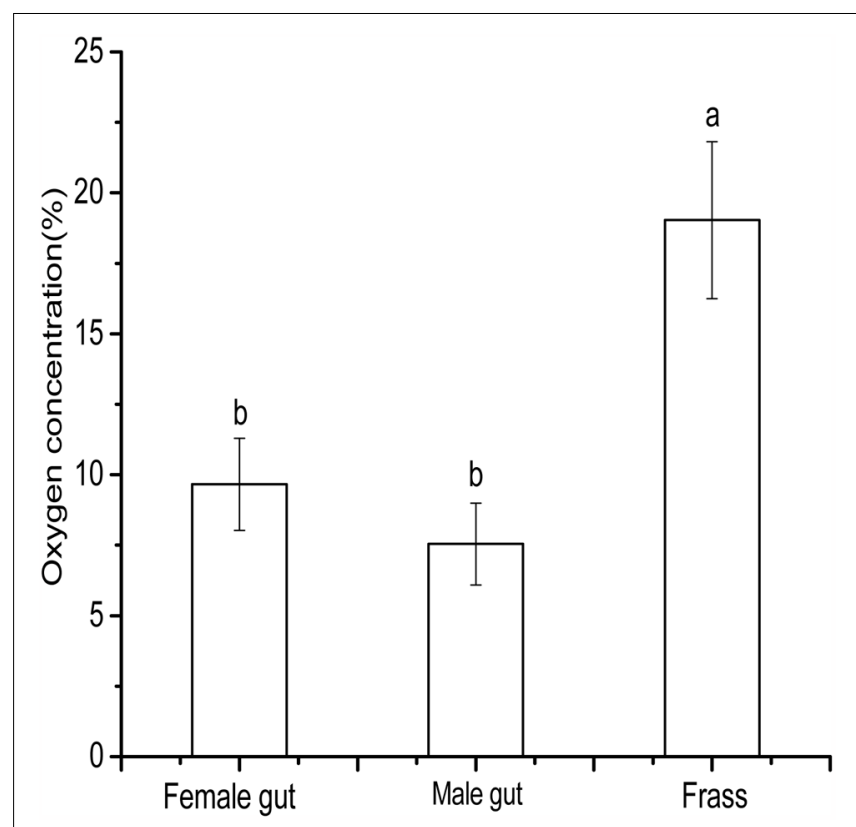

FIGURE 4 | Oxygen concentrations of Dendroctonus valens gut and frass. The bars with different letters are significantly different at $P=0.05$.

\section{DISCUSSION}

Oxygen is an important physicochemical factor that not only is required for survival of insect gut-associated aerobic bacteria but also influences their function by altering the chemical milieu of gut lumen. Hence the composition of gut-associated bacterial community and their functions vary with different levels of oxygen concentration (Brune et al., 1995). In general, the oxygen levels in the gut of herbivorous insects is considered a low oxygen environment (Johnson and Barbehenn, 2000), and little is known about oxygen levels in the gut lumen and frass of bark beetles. Thus, we initially used clark-type oxygen microelectrodes to obtain high-resolution profiles of oxygen concentrations in isolated guts and frass of $D$. valens and confirmed that the gut $(8.59 \%)$ of $D$. valens is not a strict anoxic environment and frass (19.03\%) contains an oxygen-rich environment, hence supporting our finding that no obligate anaerobic bacteria existed there. Thus, we designed experiments to evaluate the effect of gut-simulated and frass-simulated oxygen concentration environment on cis-verbenol to verbenone conversion efficiency of gut associated bacteria by comparing their activities under different oxygen concentrations.

This is the first report of gut bacterial species isolated and identified from $D$. valens from an anaerobic environment. One of the frequent bacterial species isolated was $P$. conspicua which is an enteric bacterium ubiquitous in bark beetle' $s$ gut and other general environment (Vasanthakumar et al., 2006; Delalibera et al., 2007; Morales-Jimenez et al., 2009; Nadarasah and Stavrinides, 2014), followed by E. xiangfangensis and $S$. warneri, all of which are common insect gut associates (Harada et al., 1996; Podgwaite et al., 2013; Manfredi et al., 2015)

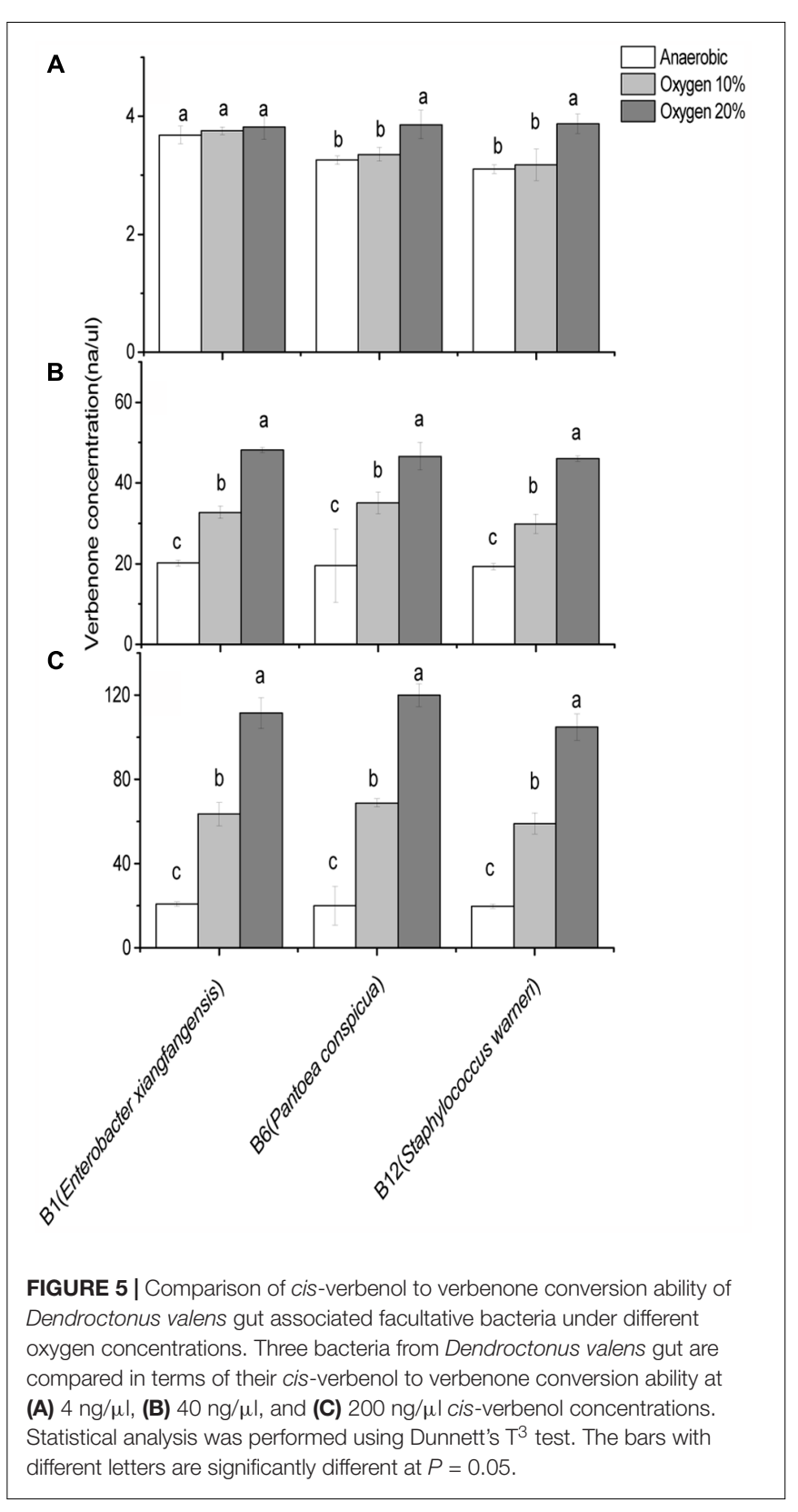

including bark beetles (Morales-Jimenez et al., 2009), e.g., P. conspicua has been found in Mexican Dendroctonus valens (19.23\% abundance) using culture-independent analysis (Morales-Jimenez et al., 2009). In general, facultative anaerobic or microaerophilic cellulolytic bacteria were often isolated in aerobic cultivation conditions from the gut of insects (Wenzel et al., 2002; Hernández et al., 2015). However, the genera Pantoea, Enterobacter, and Staphylococcus have not been reported in D. valens gut in aerobic environment (Xu et al., 2015). This discrepancy might be due to aerobic bacteria growing better than facultative anaerobic bacteria, which explains the lack of isolates of facultative anaerobic or anaerobic bacteria in aerobic environments. Our results showed that no obligate anaerobic bacteria was found in the gut of $D$. valens, which agrees with 
reports in Dendroctonus frontalis and Ips pini (Vasanthakumar et al., 2006; Delalibera et al., 2007).

A previous study used $16 \mathrm{~S}$ rRNA gene sequencing to survey gut microbial community of Dendroctonus valens and structure and abundance of different microbiota ( $\mathrm{Xu}$ et al., 2016b), while the focus of the current study is a continuation to further compare their ability to convert cis-verbenol into verbenone (a multi-functional pheromone of $D$. valens) under different $\mathrm{O}_{2}$ concentrations. Hence, a culture-dependant method is necessitated to create experimental conditions of a variable oxygen environment. We have attempted to bridge the knowledge gap (lack of species ID, and inability to vary oxygen concentration) that exists between using cultureindependent (16S rRNA) and culture-dependent methods in order to make up the shortfall and solve the research problem. To better illustrate the methodological differences, we created a table (Supplementary Table S1) to compare the gut bacteria and their abundance within each group between the two methods. The composition and abundance of microbiota in insect guts change dynamically in relation to insect feeding (Mason and Raffa, 2014) and physicochemical factors (Engel and Moran, 2013). In addition, there was a large difference in the abundance between female gut and male gut bacteria in 16S rRNA sequencing (Xu et al., 2016b), and differences are apparent when comparing the different identification methods.

The more abundant gut bacteria might not necessarily be involved in the synthesis of pheromones in the gut environment; rather it could be the nitrogen-fixation bacteria (MoralesJimenez et al., 2009) or biodegradable defense bacteria (Dillon and Dillon, 2004; Engel and Moran, 2013; Manfredi et al., 2015). On the other hand, the gut bacteria of low abundance species might be the key species to convert cis-verbenol to verbonene. Although culture-independent methods (16S rRNA sequencing) provide an unbiased approach, it could only identify the bacterial genus but couldn't positively identify the particular bacterial species or strain. Furthermore, the method doesn't allow manipulation of experimental conditions with individual strains. Other factors such as human errors, sampling or culturing methods can also resulted in the difference in abundance or absence of some strains. The gut is a low oxygen environment under normal circumstances (mean is $8.49 \%$ oxygen), and an anaerobic gut environment or oxygen rich environment cannot be controlled for in situ. Even if we could artificially vary the gut's oxygen environment, it may have limited biological significance since these conditions are far outside the observed normal range.

Furthermore, we have investigated the role of oxygen on facultative anaerobes in the chemical ecology of $D$. valens. The beetles communicate using bioactive gut volatile and verbenone (Zhang et al., 2006; Sun et al., 2013). Verbenone production in $D$. valens mainly depends upon the rate of conversion of cisverbenol and trans-verbenol to verbenone and this process is proven to be facilitated by beetles' gut-associated bacteria (Xu et al., 2015). Earlier studies on pheromone conversion had not taken into account the actual oxygen concentrations in the gut, and instead were performed at atmospheric $\mathrm{O}_{2}$ concentrations.
Hence, we have demonstrated the ability of isolated species to convert cis-verbenol into verbenone under anaerobic-aerobic conditions. Thus, until it's possible to vary the $\mathrm{O}_{2}$ concentrations in the guts in situ, the current assessment using a culture dependent is a more reasonable representation of the lower oxygen level in $D$. valens gut.

It has been clearly observed that the majority (ca. 90\%) of the isolates were able to convert cis-verbenol to verbenone in a gut-simulated oxygen environment and their conversion efficiencies increased with increasing oxygen concentration. This may be partly explained by physicochemical influence of $\mathrm{O}_{2}$ on the production of reactive oxygen species, where increased concentration of oxygen results in an increase in the amount of reactive oxygen species (Badr et al., 1989). Another possibility is that facultative bacteria have different growth rates in the environments with two distinct oxygen concentrations since oxygen tensions has already been known to inhibit or delay the growth of many aerobic or facultative anaerobic bacteria (Moore and Williams, 1911). Whether the variation of pheromone production between the three oxygen concentration environments are caused by physicochemical influence of oxygen, different growth rates or a combination of both, requires further exploration.

Previous studies of the function of gut bacteria are mostly conducted under atmospheric conditions (Xu et al., 2015; Yuki et al., 2015). In this study, the pheromone conversion efficiency by the bacteria under the gut-simulated and frasssimulated oxygen concentration environment more accurately reflects actual pheromone conversion efficiency in D. valens gut and frass, and our findings strongly suggest that oxygen concentration is a significant factor influencing pheromone production facilitated by facultative anaerobic bacteria. Since the frass of $D$. valens has been found to be a rich $\mathrm{O}_{2}$ environment, this suggests that the facultative anaerobic bacterial species capable of verbenone production can exist there. Frass appears to play a more important role in the process of attacking and the behavior regulation in the wild than previously thought, implying its important ecological significance. Future work should consider factors affecting function of gut bacteria, such as hydrogen and $\mathrm{pH}$, and studies should also involve the functions of these facultative anaerobes in $D$. valens development, detoxification, and chemical communication, which will lead to better understanding of the complex symbiotic relationship of bark beetles with microorganisms.

\section{AUTHOR CONTRIBUTIONS}

JS and ML conceived and designed the experiments. QC and LC performed the experiments and analyzed the data. QC, JW, and FA wrote the paper.

\section{FUNDING}

This work was supported by the Frontier Science Key Project of the Chinese Academy of Sciences (QYZDJ-SSW-SMC024) and 
the National Natural Science Foundation of China (31110103903 and 31222013).

\section{ACKNOWLEDGMENTS}

We thank the Forestry Bureaus of Shanxi for their assistance in field study. We thank Dr. Wei Wei (Institute of Zoology, Chinese Academy of Sciences) and Dr. Zhudong Liu (Institute of Zoology, Chinese Academy of Sciences) for technical

\section{REFERENCES}

Adams, A. S., Jordan, M. S., Adams, S. M., Suen, G., Goodwin, L. A., Davenport, K. W., et al. (2011). Cellulose-degrading bacteria associated with the invasive woodwasp Sirex noctilio. ISME J. 5, 1323-1331. doi: 10.1038/ismej. 2011.1

Badr, M. Z., Ganey, P. E., Yoshihara, H., Kauffman, F. C., and Thurman, R. G. (1989). Hepatotoxicity of menadione predominates in oxygen-rich zones of the liver lobule. J. Pharmacol. Exp. Ther. 248, 1317-1322.

Brand, J., Bracke, J., Markovetz, A., Wood, D., and Browne, L. (1975). Production of verbenol pheromone by a bacterium isolated from bark beetles. Nature 254, 136-137. doi: 10.1038/254136a0

Breznak, J. A. (2002). Phylogenetic diversity and physiology of termite gut spirochetes. Integr. Comp. Biol. 42, 313-318. doi: 10.1093/icb/42.2.313

Brune, A. (2003). “Symbionts aiding digestion," in Encyclopedia of Insects, eds V. H. Resh and R. T. Cardé (New York, NY: Academic Press), 1102-1107.

Brune, A., Emerson, D., and Breznak, J. A. (1995). The termite gut microflora as an oxygen sink: microelectrode determination of oxygen and $\mathrm{pH}$ gradients in guts of lower and higher termites. Appl. Environ. Microbiol. 61, 2681-2687.

Cheng, C., Zhou, F., Lu, M., and Sun, J. (2015). Inducible pine rosin defense mediates interactions between an invasive insect-fungal complex and newly acquired sympatric fungal associates. Integr. Zool. 10, 453-464. doi: 10.1111/ 1749-4877.12138

Darriba, D., Taboada, G. L., Doallo, R., and Posada, D. (2012). jModelTest 2: more models, new heuristics and parallel computing. Nat. Methods 9, 772-772. doi: $10.1038 /$ nmeth.2109

Delalibera, I. J., Vasanthakumar, A., Burwitz, B. J., Schloss, P. D., Klepzig, K. D., Handelsman, J., et al. (2007). Composition of the bacterial community in the gut of the pine engraver, Ips pini (Say) (Coloptera) colonizing red pine. Symbiosis 43, 97-104.

Dillon, R. J., and Dillon, V. M. (2004). The gut bacterial of insects: nonpathogenic interactions. Annu. Rev. Entomol. 47, 71-92. doi: 10.1146/annurev.ento.49. 061802.123416

Dillon, R. J., Vennard, C. T., and Charnley, A. K. (2000). Pheromones: exploitation of gut bacteria in the locust. Nature 403, 851-851. doi: 10.1038/35002669

Dillon, R. J., Vennard, C. T., and Charnley, A. K. (2002). A note: gut bacteria produce components of a locust cohesion pheromone. J. Appl. Microbiol. 92, 759-763. doi: 10.1046/j.1365-2672.2002.01581.x

Dytham, C. (2011). Choosing and Using Statistics: A Biologist's Guide. Oxford: Wiley-Blackwell.

Engel, P., and Moran, N. A. (2013). The gut microbiota of insects - diversity in structure and function. FEMS Microbiol. Rev. 37, 699-735. doi: 10.1111/15746976.12025

Farjon, A., and Page, C. N. (1999). Conifers: Status Survey and Conservation Action Plan. Gland: IUCN.

Gitau, C., Bashford, R., Carnegie, A., and Gurr, G. (2013). A review of semiochemicals associated with bark beetle (Coleoptera: Curculionidae: Scolytinae) pests of coniferous trees: a focus on beetle interactions with other pests and their associates. For. Ecol. Manag. 297, 1-14. doi: 10.1016/j.foreco. 2013.02.019

Hall, T. A. (1999). BioEdit: a user-friendly biological sequence alignment editor and analysis program for Windows 95/98/NT. Nucleic Acids Symp. Ser. 41, 95-98. guidance and field assistance. We thank Drs. Letian $\mathrm{Xu}$ and Chihang Cheng for reviews of earlier versions of the manuscript.

\section{SUPPLEMENTARY MATERIAL}

The Supplementary Material for this article can be found online at: https://www.frontiersin.org/articles/10.3389/fmicb. 2018.00464/full\#supplementary-material

Harada, H., Oyaizu, H., and Ishikawa, H. (1996). A consideration about the origin of aphid intracellular symbiont in connection with gut bacterial flora. J. Gen. Appl. Microbiol. 42, 17-26. doi: 10.2323/jgam.42.17

Hernández, N., Escudero, J. A., Millán, Á. S., González-Zorn, B., Lobo, J. M., Verdú, J. R., et al. (2015). Culturable aerobic and facultative bacteria from the gut of the polyphagic dung beetle Thorectes lusitanicus. Insect Sci. 22, 178-190. doi: 10.1111/1744-7917.12094

Hillis, D., and Bull, J. (1993). An empirical test of bootstrapping as a method for assessing confidence in phylogenetic analysis. Syst. Biol. 42, 182-192. doi: 10.1093/sysbio/42.2.182

Johnson, K. S., and Barbehenn, V. R. (2000). Oxygen levels in the gut lumens of herbivorous insects. J. Insect Physiol. 46, 897-903. doi: 10.1016/S0022-1910(99) 00196-1

Kaufman, M. G., and Klug, M. J. (1991). The contribution of hindgut bacteria to dietary carbohydrate utilization by crickets (Orthoptera: Gryllidae). Comp. Biochem. Physiol. 98, 117-123. doi: 10.1016/0300-9629(91)90588-4

Kim, O. S., Cho, Y. J., Lee, K., Yoon, S. H., Kim, M., and Na, H. (2012). Introducing EzTaxon-e: a prokaryotic 16S rRNA gene sequence database with phylotypes that represent uncultured species. Int. J. Syst. Evol. Microbiol. 62, 716-721. doi: 10.1099/ijs.0.038075-0

Kwon, Y., and Ricke, S. (1998). Survival of a Salmonella typhimurium poultry isolate in the presence of propionic acid under aerobic and anaerobic conditions. Anaerobe 4, 251-256. doi: 10.1006/anae.1998.0177

Lou, Q., Lu, M., and Sun, J. (2014). Yeast diversity associated with invasive Dendroctonus valens killing Pinus tabuliformis in China using culturing and molecular methods. Microb. Ecol. 68, 397-415. doi: 10.1007/s00248-0140413-6

Lu, M., Hulcr, J., and Sun, J. (2016). The role of symbiotic microbes in insect invasions. Annu. Rev. Ecol. Evol. Syst. 47, 487-505. doi: 10.1146/annurevecolsys-121415-032050

Manfredi, A. P., Perotti, N. I., and Martínez, M. A. (2015). Cellulose degrading bacteria isolated from industrial samples and the gut of native insects from Northwest of Argentina. J. Basic Microbiol. 55, 1384-1393. doi: 10.1002/jobm. 201500269

Mason, C. J., Couture, J. J., and Raffa, K. F. (2014). Plant-associated bacteria degrade defense chemicals and reduce their adverse effects on an insect defoliator. Oecologia 175, 901-910. doi: 10.1007/s00442-014-2950-6

Mason, C. J., and Raffa, K. F. (2014). Acquisition and structuring of midgut bacterial communities in gypsy moth (Lepidoptera: Erebidae) larvae. Environ. Entomol. 43, 595-604. doi: 10.1603/EN14031

Miao, Z., Chou, W., Huo, F., Wang, X., Fang, J., and Zhao, M. (2001). Biology of Dendroctonus valens in Shanxi province. Shanxi For. Sci. Technol. 23, 34-37.

Moore, B., and Williams, R. S. (1911). The growth of various species of bacteria and other micro-organisms in atmospheres enriched with oxygen. Biochem. J. 5, 181-187. doi: 10.1042/bj0050181

Morales-Jimenez, J., Zuniga, G., Villa-Tanaca, L., and Hernandez-Rodriguez, C. (2009). Bacterial community and nitrogen fixation in the red turpentine beetle, Dendroctonus valens LeConte (Coleoptera: Curculionidae: Scolytinae). Microb. Ecol. 58, 879-891. doi: 10.1007/s00248-009-9548-2

Moran, N. A., Russell, J. A., Koga, R., and Fukatsu, T. (2005). Evolutionary relationships of three new species of Enterobacteriaceae living as symbionts of aphids and other insects. Appl. Environ. Microbiol. 71, 3302-3310. doi: 10.1128/ AEM.71.6.3302-3310.2005 
Nadarasah, G., and Stavrinides, J. (2014). Quantitative evaluation of the hostcolonizing capabilities of the enteric bacterium Pantoea using plant and insect hosts. Microbiology 160, 602-615. doi: 10.1099/mic.0.073452-0

Paine, T., Raffa, K., and Harrington, T. (1997). Interactions among scolytid bark beetles, their associated fungi, and live host conifers. Annu. Rev. Entomol. 42, 179-206. doi: 10.1146/annurev.ento.42.1.179

Podgwaite, J. D., D’Amico, V., Zerillo, R. T., and Schoenfeldt, H. (2013). Bacteria associated with larvae and adults of the Asian longhorned beetle (Coleoptera: Cerambycidae). J. Entomol. Sci. 48, 128-138. doi: 10.18474/0749-8004-48.2.128

Posada, D., and Buckley, T. R. (2004). Model selection and model averaging in phylogenetics: advantages of Akaike information criterion and Bayesian approaches over likelihood ratio tests. Syst. Biol. 53, 793-808. doi: 10.1080/ 10635150490522304

Raffa, K. F., and Berryman, A. A. (1987). Interacting selective pressures in coniferbark beetle systems: a basis for reciprocal adaptations? Am. Nat. 129, 234-262. doi: $10.1086 / 284633$

Renwick, J. A., Hughes, P. R., and Krull, I. S. (1976). Selective production of cis- and trans-verbenol from (-)-and (+)-alpha by a bark beetle. Science 191, 199-201. doi: 10.1126/science.1246609

Sharon, G., Segal, D., Ringo, J. M., Hefetz, A., Zilber-Rosenberg, I., and Rosenberg, E. (2010). Commensal bacteria play a role in mating preference of Drosophila melanogaster. Proc. Natl. Acad. Sci. U.S.A. 107, 20051-20056. doi: 10.1073/pnas.1009906107

Stamatakis, A., Ludwig, T., and Meier, H. (2004). “A fast program for maximum likelihood-based inference of large phylogenetic trees," in Proceedings of the 2004 ACM Symposium on Applied Computing (New York City, NY: ACM), 197-201. doi: 10.1145/967900.967940

Stöver, B. C., and Müller, K. F. (2010). TreeGraph 2: combining and visualizing evidence from different phylogenetic analyses. BMC Bioinformatics 11:7. doi: 10.1186/1471-2105-11-7

Sun, J., Lu, M., Gillette, N. E., and Wingfield, M. J. (2013). Red turpentine beetle: innocuous native becomes invasive tree killer in China. Annu. Rev. Entomol. 58, 293-311. doi: 10.1146/annurev-ento-120811-153624

Tamura, K., Peterson, D., Peterson, N., Stecher, G., Nei, M., and Kumar, S. (2011). MEGA5: molecular evolutionary genetics analysis using maximum likelihood, evolutionary distance, and maximum parsimony methods. Mol. Biol. Evol. 28, 2731-2739. doi: 10.1093/molbev/msr121

Thompson, J. D., Gibson, T. J., Plewniak, F., Jeanmougin, F., and Higgins, D. G. (1997). The CLUSTAL_X windows interface: flexible strategies for multiple sequence alignment aided by quality analysis tools. Nucleic Acids Res. 25, 4876-4882. doi: 10.1093/nar/25.24.4876

Vasanthakumar, A., Delalibera, I., Handelsman, J., Klepzig, K. D., Schloss, P. D., and Raffa, K. F. (2006). Characterization of gut-associated bacteria in larvae and adults of the southern pine beetle, Dendroctonus frontalis Zimmermann. Environ. Entomol. 35, 1710-1717. doi: 10.1093/ee/35.6.1710

Wada-Katsumata, A., Zurek, L., Nalyanya, G., Roelofs, W. L., Zhang, A., and Schal, C. (2015). Gut bacteria mediate aggregation in the German cockroach. Proc. Natl. Acad. Sci. U.S.A. 112, 15678-15683. doi:10.1073/pnas.1504031112

Wang, B., Salcedo, C., Lu, M., and Sun, J. (2012). Mutual interactions between an invasive bark beetle and its associated fungi. Bull. Entomol. Res. 102, 71-77. doi: 10.1017/S000748531100037X
Wang, S., Zhou, F., Wang, B., Xu, D., Cao, Q., Lu, M., et al. (2017). Volatiles produced by bacteria alleviate antagonistic effects of one associated fungus on Dendroctonus valens larvae. Sci. China Life Sci. 60, 924-926. doi: 10.1007/ s11427-017-9073-9

Weisburg, W. G., Barns, S. M., Pelletier, D. A., and Lane, D. J. (1991). 16S ribosomal DNA amplification for phylogenetic study. J. Bacteriol. 173, 697-703. doi: 10.1128/jb.173.2.697-703.1991

Wenzel, M., Schönig, I., Berchtold, M., Kämpfer, P., and König, H. (2002). Aerobic and facultatively anaerobic cellulolytic bacteria from the gut of the termite Zootermopsis angusticollis. J. Appl. Microbiol. 92, 32-40. doi: 10.1046/j.13652672.2002.01502.x

Xu, L., Lou, Q., Cheng, C., Lu, M., and Sun, J. (2015). Gut-associated bacteria of Dendroctonus valens and their involvement in verbenone production. Microb. Ecol. 70, 1012-1023. doi: 10.1007/s00248-015-0625-4

$\mathrm{Xu}, \mathrm{L} ., \mathrm{Lu}, \mathrm{M}$., and Sun, J. (2016a). Invasive bark beetle-associated microbes degrade a host defensive monoterpene. Insect Sci. 23, 183-190. doi: 10.1111/ 1744-7917.12255

Xu, L., Lu, M., Xu, D., Cheng, L., and Sun, J. (2016b). Sexual variation of bacterial microbiota of Dendroctonus valens guts and frass in relation to verbenone production. J. Insect Physiol. 95, 110-117. doi: 10.1016/j.jinsphys.2016.09.014

Xu, L., Shi, Z., Wang, B. L., Lu, M., and Sun, J. (2016c). Pine defensive monoterpene a-Pinene influences the feeding behavior of Dendroctonus valens and its gut bacterial community structure. Int. J. Mol. Sci. 17, 1711-1734. doi: 10.3390/ ijms 17111734

Yuki, M., Kuwahara, H., Shintani, M., Izawa, K., Sato, T., Starns, D., et al. (2015). Dominant ectosymbiotic bacteria of cellulolytic protists in the termite gut also have the potential to digest lignocellulose. Environ. Microbiol. 17, 4942-4953. doi: $10.1111 / 1462-2920.12945$

Zhang, L., Sun, J., and Clarke, S. (2006). Effects of verbenone dose and enantiomer on the interruption of response of the red turpentine beetle, Dendroctonus valens LeConte (Coleoptera: Scolytidae), to its Kariomones. Environ. Entomol. 35, 655-660. doi: 10.1603/0046-225X-35.3.655

Zhou, F., Lou, Q., Wang, B., Xu, L., Cheng, C., Lu, M., et al. (2016). Altered carbohydrates allocation by associated bacteria-fungi interactions in a bark beetle-microbe symbiosis. Sci. Rep. 6:20135. doi: 10.1038/srep20135

Zhou, F., Xu, L., Wang, S., Wang, B., Lou, Q., Lu, M., et al. (2017). Bacterial volatile ammonia regulates the consumption sequence of D-pinitol and D-glucose in a fungus associated with an invasive bark beetle. ISME J. 11, 2809-2820. doi: 10.1038 /ismej.2017.131

Conflict of Interest Statement: The authors declare that the research was conducted in the absence of any commercial or financial relationships that could be construed as a potential conflict of interest.

Copyright (C) 2018 Cao, Wickham, Chen, Ahmad, Lu and Sun. This is an open-access article distributed under the terms of the Creative Commons Attribution License (CC BY). The use, distribution or reproduction in other forums is permitted, provided the original author(s) and the copyright owner are credited and that the original publication in this journal is cited, in accordance with accepted academic practice. No use, distribution or reproduction is permitted which does not comply with these terms. 